\title{
Histopathological Study of Lung Biopsy in Association with Immunohistochemistry
}

\author{
Nirali Lad ${ }^{1}$, Meena Daveshwar² \\ ${ }^{1}$ Department of Pathology, Medical College and SSG Hospital, Vadodara, Gujarat, India. \\ ${ }^{2}$ Department of Pathology, Medical College and SSG Hospital, Vadodara, Gujarat, India.
}

\section{ABSTRACT}

\section{BACKGROUND}

Lungs are the most exposed organs to different aggressions because of their anatomical and histological particularities. Lung lesions are common due to exposure to various risk factors. A few of them are pollution, smoking, human immunodeficiency virus (HIV), infections, tuberculosis, and malnutrition. An increasing trend in cases of lung cancer is being seen in India. Lung biopsy is a simple, relatively safe, rapid and reliable technique for the diagnosis of pulmonary mass lesions, particularly with the aid of computed tomography (CT) scan. We wanted to study the histopathological pattern of lung lesions along with its distribution with regard to age, sex, and site.

\section{METHODS}

This is an observational study conducted at the Department of Pathology, Medical College and SSG Hospital, Vadodara, from October 2016 to October 2018. Material for the study consisted of all the biopsies submitted for histopathological and immunohistochemical study.

\section{RESULTS}

82 cases were included in the study, out of which 52 cases $(63.41 \%)$ were malignant, 5 cases $(6.10 \%)$ were of inflammatory origin and 25 cases $(30.49 \%)$ showed no evidence of malignancy. Male to Female ratio was 3:1. Most common age group was 51 to 60 years (31.71\%). Most common histological type of malignancy was adenocarcinoma (36.54\%), followed by squamous cell carcinoma $(30.77 \%)$.

\section{CONCLUSIONS}

Lung biopsy is reliable with high accuracy for diagnosis and subtyping of lung lesions. Immunohistochemistry is an important complimentary tool for routine diagnosis of lung cancers.

\section{KEY WORDS}

Lung Biopsy, Lung Tumours, Histological Type, Immunohistochemistry
Corresponding Author: Dr. Nirali Lad, D/93, Sundarvan Society, Near Abhilasha Cross Road, New Sama Road,

Vadodara-390024,

Gujarat, India.

E-mail: niralilad21@gmail.com

DOI: $10.14260 / j e m d s / 2019 / 779$

Financial or Other Competing Interests: None.

How to Cite This Article:

Lad N, Daveshwar M. Histopathological study of lung biopsy in association with immunohistochemistry. J. Evolution Med. Dent. Sci. 2019;8(48):3609-3612, DOI: $10.14260 /$ jemds $/ 2019 / 779$

Submission 08-07-2019,

Peer Review 14-11-2019,

Acceptance 20-11-2019,

Published 02-12-2019. 


\section{BACKGROUND}

Lungs are the most exposed organs to different aggressions because of their anatomical and histological particularities. Lung lesions are common due to exposure to various risk factors. A few of them are pollution, smoking, human immunodeficiency virus (HIV), infections, tuberculosis, and malnutrition.

Pulmonary tuberculosis is the most common infectious disease in the world with an estimated one-third of the population infected and 2.5 million deaths annually. In India, the incidence of pulmonary tuberculosis is $160 / 100,000$ and the prevalence is $312 / 100,000.1,2$ There are 10 to $15 \%$ of diffuse interstitial lung disease patients in large hospitals in India and $50 \%$ are idiopathic. ${ }^{1}$ COPD is the second most common pulmonary lesion in India after pulmonary tuberculosis. ${ }^{1}$ The overall lung cancer incidence rate is increased from 38.4 per 100,000 person-years during 1977 to 1981 to peak at 43.5 per 100,000 person-years during 1987 to 1991 and then decreased to 33.6 per 100,000 person-years during 2006 to $2010 .^{3}$ Lung cancer causes 36,000 deaths per year in UK, $25 \%$ of all cancer deaths, $8 \%$ of male deaths and $4 \%$ of female deaths and $49.9 \%$ cases in developing countries.1,2 An increasing trend in cases of lung cancer is seen in India. The National Cancer Registry Programme of the Indian Council of Medical Research(ICMR) has developed a cancer atlas for India and its report in 200102 has revealed that North-east states are 'hot-spots' for lung cancer and has the highest incidence rate. ${ }^{1}$

Lung biopsy is a simple, relatively safe, rapid and reliable technique for the diagnosis of pulmonary mass lesions, particularly with the aid of computed tomography (CT) scan. Lung mass that persists or grow and larger than $3 \mathrm{~cm}$ should be biopsied if possible. Biopsy not only distinguishes between benign and malignant lesions but also helps in typing of lung cancer, so initiation of specific therapy like chemotherapy or surgery is possible without unnecessary delay. Histopathological examination plays an important role in making a correct and accurate diagnosis of various lesions of the lung, which has profound impact on the further management of patients. Various types of non-malignant lesions like infections, vasculitis, some connective tissue diseases, amyloidosis, bronchial and vascular abnormalities and malignant lesions like adenocarcinoma, squamous cells carcinoma, small cell and non-small cell carcinoma, metastatic tumour can be accurately diagnosed by this method. Although Haematoxylin and Eosin stain is the gold standard method used for diagnosis, immunohistochemistry can enhance the accuracy of such analysis. Immunohistochemistry can be used in the routine diagnosis of pulmonary tumours in order to identify biological markers (Diagnostic and prognostic).

\section{METHODS}

This observational study was conducted at the Department of Pathology, Medical College and SSG Hospital, Vadodara from October 2016 to October 2018. We studied all 82 cases of lung biopsies, that was received within 2 years and were subjected to histopathological examination and IHC stain for confirmation whenever required. IHC markers were used when diagnosis cannot be made only by $\mathrm{H}$ \& E sections. Depending upon a malignant cells' pattern and structure on $\mathrm{H}$ \& E sections, IHC markers were selected and applied and according to results, diagnosis was made.

\section{Statistical Analysis}

The data analysis was done by descriptive statistics for a percentage of different type of lung lesions and distribute them by age and sex.

\section{RESULTS}

In present study of 82 cases of lung biopsy, 52 cases (63.41\%) were malignant, 5 cases $(6.10 \%)$ were of inflammatory conditions and 25 cases $(30.49 \%)$ showed no evidence of malignancy. 65 cases $(79.27 \%)$ were Male and 17 cases $(20.73 \%)$ were female with male to female ratio of $3: 1$. Age ranged from 11 to 80 years with majority of the cases were in the in the age group of 51 to 60 years (26 cases, $31.71 \%$ ), followed by 61 to 70 years (21 Cases, $25.61 \%$ ). Out of total 52 malignant cases in this study, 39 (75\%) were Male and $13(25 \%)$ were female patients. According to the histopathological diagnosis, the most common malignant lesion in this study was adenocarcinoma (19 cases, 36.54\%), followed by squamous cell carcinoma (16 cases, $30.77 \%$ ), 4 cases of small cell carcinoma (7.69\%), 3 cases of non-small cell carcinoma NOS (5.78\%).

\begin{tabular}{|c|c|c|}
\hline \multirow{2}{*}{ Diagnosis } & \multicolumn{2}{|c|}{ Malignant Lesions (n= 52) } \\
\cline { 2 - 3 } & Number & \%age \\
\hline Adenocarcinoma & 19 & $36.54 \%$ \\
\hline Adenosquamous carcinoma & 01 & $1.92 \%$ \\
\hline Carcinoid tumour & 01 & $1.92 \%$ \\
\hline Lymphoblastic lymphoma & 02 & $3.85 \%$ \\
\hline Non-small cell carcinoma & 02 & $3.85 \%$ \\
\hline Poorly differentiated adenocarcinoma & 01 & $1.92 \%$ \\
\hline Non-small cell lung carcinoma, NOS & 03 & $5.78 \%$ \\
\hline Poorly differentiated squamous cell carcinoma & 01 & $1.92 \%$ \\
\hline Small cell carcinoma & 04 & $7.69 \%$ \\
\hline Small cell neuroendocrine tumour & 01 & $1.92 \%$ \\
\hline Squamous cell carcinoma & 16 & $30.77 \%$ \\
\hline Synovial sarcoma & 01 & $1.92 \%$ \\
\hline Total & $\mathbf{5 2}$ & $\mathbf{1 0 0} \%$ \\
\hline Table 1. Histopathological Diagnoses of Malignant Lesions
\end{tabular}

\begin{tabular}{|c|c|c|c|}
\hline Sr. & Diagnosis & \multicolumn{2}{|c|}{ IHC Markers } \\
\cline { 3 - 4 } No. & Adenocarcinoma & Positive & Negative \\
\hline 1. & CK7, TTF-1 & CK5/6, p63 \\
\hline 2. & Squamous cell carcinoma & CK5/6, p63 & CK7, TTF-1 \\
\hline 3. & $\begin{array}{c}\text { Adenosquamous } \\
\text { carcinoma }\end{array}$ & $\begin{array}{c}\text { CK5/6, p63 (in squamoid areas), } \\
\text { CK7 (in glandular areas) }\end{array}$ & - \\
\hline 4. & Carcinoid tumour & $\begin{array}{c}\text { Pankeratin, Synaptophysin, } \\
\text { Chromogranin }\end{array}$ & - \\
\hline 5. & $\begin{array}{c}\text { Lymphoblastic } \\
\text { lymphoma }\end{array}$ & $\begin{array}{c}\text { CD99, CD2, CD5, } \\
\text { LCA,CD20,Pankeratin, }\end{array}$ & $\begin{array}{c}\text { CD1a, S100 } \\
\text { Chromoptophysin, }\end{array}$ \\
\hline 6. & $\begin{array}{c}\text { Poorly differentiated } \\
\text { squamous cell carcinoma }\end{array}$ & $\begin{array}{c}\text { P63, } \\
\text { CK5/6 }\end{array}$ & $\begin{array}{c}\text { Synaptophysin, } \\
\text { Chromogranin }\end{array}$ \\
\hline 7. & $\begin{array}{c}\text { Non-small cell lung } \\
\text { carcinoma, NOS }\end{array}$ & Pankeratin & $\begin{array}{c}\text { P63, CK5/6, CK7, } \\
\text { Synaptophysin,- } \\
\text { Chromogranin }\end{array}$ \\
\hline 8. & Small cell carcinoma & Synaptophysin, Chromogranin & - \\
\hline 9. & Synovial sarcoma & BCL-2, CD99 & S100, Calretinin \\
\hline
\end{tabular}

Table 2. Results of IHC Markers in Different Histological Types of Lung Cancer 
In males, there were 15 cases of adenocarcinoma (38.47\%) and 15 cases of squamous cell carcinoma (38.47\%), followed by 2 cases of non-small cell lung carcinoma, NOS (5.13\%). In females, adenocarcinoma was seen in 4 cases $(30.58 \%)$ among the other carcinoma detected. Out of 5 cases of inflammatory lesions, two cases were of nonspecific inflammation, the other 3 were of granulomatous inflammation, tuberculous inflammation, and desquamative interstitial pneumonia. In present study, immunohistochemistry was applied in 38 cases. With the use of IHC markers, diagnosis of adenocarcinoma, squamous cell carcinoma, adenosquamous carcinoma, lymphoblastic lymphoma, carcinoid tumour, non-small cell lung carcinoma, NOS, poorly differentiated squamous cell carcinoma, small cell carcinoma, and synovial sarcoma have been confirmed.

\section{DISCUSSION}

Lung biopsy is widely recognized as a valuable tool for the diagnosis and management of diverse pulmonary disorders. Transbronchial lung biopsy, open lung biopsy, and CT guided core needle biopsy are the principal tools that have been developed for obtaining lung tissue for histopathological examination.

CT-guided percutaneous needle biopsy of the lung is commonly used as an outpatient diagnostic procedure and is relatively safe, sensitive and accurate method of diagnosing benign and malignant lesions as well as suitable for obtaining tissue samples of sufficient quantity and quality for allowing molecular analysis of biomarkers. Image-guided approaches also allow biopsy from areas of the tumour felt most likely to harbour viable tumour (i.e., avoiding centrally necrotic areas) and representative of whole tumour. TruCut biopsy is very helpful in early diagnosis and less invasive as compared to excision especially to differentiate benign from malignant tumour and when oncosurgeon is planning pre-operative chemotherapy or in advanced disease and in small cell carcinoma where surgery is not recommended.

The incidence rate of malignant lesions in the present study $(63.41 \%)$ was similar to the study of Kinnari S. Naik et $\mathrm{al}^{3}(75.6 \%)$ and Pradeep Kumar Giri et $\mathrm{al}^{4}(75 \%)$. The incidence rate of inflammatory conditions was $6.10 \%$ in the present study as compared to $15.4 \%$ and $22.5 \%$ in the study of Kinnari S. Naik et $\mathrm{al}^{3}$ and Pradeep Kumar Giri et $\mathrm{al}^{4}$ respectively. The male to female ratio in present study was $3: 1$, which was almost similar to Kinnari S. Naik et $\mathrm{al}^{3}$ study (2:1), Pradeep Kumar Giri et al ${ }^{4}$ study (2.75:1).

In the present study, maximum malignant cases were seen in the age group of 61 to 70 years, which was similar to Anjan Das et $\mathrm{al}^{5}$ study. The incidence rate was $25 \%$ in the age group of 51 to 60 years in the present study which almost similar to Pradeep Kumar Giri et $\mathrm{al}^{4}$ study, which was $20 \%$.

Present study and study by Pradeep Kumar Giri et $\mathrm{al}^{4}$, Kinnari S. Naik et $\mathrm{al}^{3}$ and Deependra K Rai et $\mathrm{al}^{6}$ showed similar result with predominance of adenocarcinoma followed by squamous cell carcinoma and small cell carcinoma. The incidence rate of adenocarcinoma (36.54\%) and squamous cell carcinoma $(30.77 \%)$ in the present study were almost similar to Kinnari S. Naik et $\mathrm{al}^{3}$ study with the incidence rate of $38 \%$ and $22.4 \%$ respectively.
When comparing the characteristics of the lung cancer cases, squamous cell carcinoma was the predominant type of lung cancer among men but women were found to be more likely to have adenocarcinoma as compared to men and this was consistent with Kinnari S. Naik et $\mathrm{al}^{3}$ and Kumar et al. ${ }^{7}$ The incidence of tuberculous inflammation was almost similar in the study of Pradeep Kumar Giri et $\mathrm{al}^{4}$ (11.1\%) and present study (20\%).

In an era of precision medicine, immunohistochemistry plays a critical role in the classification of tumours into subtypes and for assessing biomarkers for timely and accurate therapeutic decision-making. Compared with other techniques, immunohistochemistry has a number of advantages, including being widely available, technically less challenging, and cost-efficient with a rapid turn-around time. Thus, molecular-specific immunohistochemical assays have huge potential as practical screening tools for the detection of druggable genetic alterations and for the assessment of biomarkers for molecular- targeted therapy. In addition, immunohistochemistry can be interpreted using fewer tumour cells than are required for other molecular techniques. Moreover, immunohistochemistry allows for the evaluation of cellular localization and staining patterns in the context of tumour structures; thus, a greater range of information is provided.

In present study, immunohistochemistry was performed in total 38 cases. Out of 19 cases of adenocarcinoma, IHC was performed in 15 cases for confirmation of diagnosis. Rest of 4 cases were diagnosed on $\mathrm{H} \& \mathrm{E}$ sections. IHC markers, that have been applied were, CK7, TTF-1, CK5/6, and p63. All the 15 cases were positive for CK7 and TTF-1 whereas negative for CK5/6 and p63. These results showed concordance with Kinnari S. Naik et $\mathrm{al}^{3}$ other studies.8,9,10 Out of 16 cases of squamous cell carcinoma, 4 cases were diagnosed on $\mathrm{H}$ \& $\mathrm{E}$ sections and rest of 12 cases were confirmed by immunohistochemistry. IHC markers, that have been applied were, p63, CK5/6, CK7, and TTF-1. All the cases were positive for CK5/6 and p63 whereas negative for CK7 and TTF-1. These results showed concordance with Kinnari S. Naik et al, ${ }^{3}$ Rekhtman et al ${ }^{11}$ and Nicholson et al. ${ }^{12}$

A case of adenosquamous carcinoma was confirmed by using CK7, p63, and CK5/6. CK7 was positive in glandular areas whereas CK5/6 and p63 were positive in squamoid areas. In the case of lymphoblastic lymphoma, microscopically, there was a monomorphic population of atypical lymphoid cells with fine nuclear chromatin and convoluted nucleus. IHC markers, CD2, CD5, CD99, CD20, CD1a, LCA, S100, Synaptophysin, and chromogranin were applied. Out of which, CD2, CD5, CD20, CD99, and LCA were positive. So according to this result lymphoblastic lymphoma diagnosis was given. In a case of carcinoid tumour, microscopically, tumour cells were monomorphic, hyper chromatic showing finely granular chromatin and eosinophilic cytoplasm. IHC markers synaptophysin, chromogranin, and pankeratin were applied for confirmation. All markers were positive.

In case of non-small cell lung carcinoma, NOS type, microscopically tumour cells were hyper chromatic showing indistinct cell border and moderate cytoplasm. IHC markers P63, CK5/6, CK7, synaptophysin, chromogranin, and pankeratin were applied for subtyping of non-small cell carcinoma. Only pankeratin was positive, so non-small cell 
lung carcinoma, NOS diagnosis was given. Poorly differentiated squamous cell carcinoma was confirmed by applying IHC markers, CK5/6, p63, synaptophysin and chromogranin. Only CK5/6 was positive and other markers were negative. Out of 4 cases of small cell carcinoma, one case was diagnosed on $\mathrm{H} \& \mathrm{E}$ sections. Other cases were confirmed by using IHC markers, synaptophysin and chromogranin. These markers were positive in all three cases. In a case of synovial sarcoma, microscopically tumour was composed of solid sheets of round to spindle cells with intervening hemangiopericytoma-like vessels. Cells were hyper chromatic and having high nuclear to cytoplasmic ratio. BCL-2, CD99, S100, and calretinin IHC markers were applied for confirmation. BCL-2 and CD99 were positive.

\section{CONCLUSIONS}

Lung biopsy is reliable with high accuracy for diagnosis and subtyping of lung lesions. Histopathological examination plays an important role in making a correct and accurate diagnosis of various lesions of lung. Although Haematoxylin and Eosin stain is the gold standard method used for diagnosis, immunohistochemistry is an important complimentary tool for routine diagnosis of lung cancers. In our study most common histological type was adenocarcinoma, followed by squamous cell carcinoma. Male to female ratio was $3: 1$. With the use of IHC markers, diagnosis of adenocarcinoma, squamous cell carcinoma, adenosquamous carcinoma, lymphoblastic lymphoma, carcinoid tumour, non-small cell carcinoma, NOS, poorly differentiated squamous cell carcinoma, small cell carcinoma, and synovial saroma can be confirmed.

\section{REFERENCES}

[1] Shah SK. Pulmonology. In: Shah SN, Paul AM, Billimori AR, Munjal YP, et al. eds. API Textbook of Medicine. $8^{\text {th }}$ edn. Mumbai: The Association of Physicians of India 2008: p. 382-425.

[2] Haslett C, Chilvers ER. Respiratory disease. In: Haslett C, Chilvers ER, Boon NA, et al. eds. Davidson's Principle and practice of medicine. 19th edn. Philadelphia: Churchill Livingstone 2002: p. 483-574.
[3] Naik KS, Jarag M, Shah P, et al. Shifting trends of lung tumours and its diagnosis by lung biopsy: a study of 78 cases. Int J Res Med Sci 2015;3(12):3524-9.

[4] Giri PK, Pradhan G, Patnaik M, et al. Evaluation of peripheral lung masses with special reference to ultrasound-guided fine needle aspiration cytology: a clinico-radiological and pathological study. Int J Sci Stud 2017;4(10):19-23.

[5] Das A, Rokhum A, Sinha K. Clinicopathological profile of lung cancer in a tertiary medical centre in Tripura, a north-east state. J Evolution Med Dent Sci 2017;6(16):1260-3.

[6] Rai DK, Kumar A, Kumar A, et al. A clinico-radiological and pathological profile of patients of lung cancer presenting to All India Institute of Medical Sciences (Patna). East J Med Sci 2017;2(1):8-11.

[7] Kumar M, Sharma DK, Garg M, et al. Clinicopathological profile of lung cancer-changing trends in India. Int J Res Med 2016;5:57-62.

[8] Mukhopadhyay S, Katzenstein AL. Subclassification of non-small cell lung carcinomas lacking morphologic differentiation on biopsy specimens: utility of an immunohistochemical panel containing TTF-1, napsin A, p63 and CK5/6. Am J Surg Pathol 2011;35(1):15-25.

[9] Zhang H, Liu J, Cagle PT, et al. Distinction of pulmonary small cell carcinoma from poorly differentiated squamous cell carcinoma: an immunohistochemical approach. Mod Pathol 2005;18(1):111-8.

[10] Jerome MV, Mazieres J, Groussard 0, et al. Expression of TTF-1 and cytokeratins in primary and secondary epithelial lung tumours: correlation with histological type and grade. Histopathology 2004;45(2):125-34.

[11] Rekhtman N, Ang DC, Sima CS, et al. Immunohistochemical algorithm for differentiation of lung adenocarcinoma and squamous cell carcinoma based on large series of whole-tissue sections with validation in small specimens. Mod Pathol 2011;24(10):1348-59.

[12] Nicholson AG, Gonzalez D, Shah P, et al. Refining the diagnosis and EGFR status of non-small cell lung carcinoma in biopsy and cytologic material, using a panel of mucin staining, TTF-1, cytokeratin 5/6, P63 and EGFR mutation analysis. J Thorac Oncol 2010;5(4):436-41. 